\title{
Competitive Priorities and Innovation in SMEs:A Brazil Multi-Case Study
}

\author{
Felipe Ferreira de Lara', Márcia Regina Neves Guimarães²
}

\begin{abstract}
This study uses the qualitative approach and the multi-case study method to analyze the influence that the competitive advantages exerts in the innovation given the specific context of the research. Among the main results are the mains factors that generate innovative practices in the researched companies are quality, flexibility, delivery and cost, in this order of importance, as generators of innovation practices in the surveyed companies. The quality and flexibility were related to technological product and process innovations. In the non-technological innovations, quality influenced the marketing and organizational innovations. Flexibility generated marketing innovations and cost and delivery generated organizational innovation. The results of this research can make it easy to redirect future public innovation policies in small businesses. We discovered that innovation does not occur only through the acquisitions and heavy investments in technology. The strategic reorganization of the decision-taking processes can contribute to innovation.
\end{abstract}

Keywords: production strategies; competitive priorities; innovation; small businesses; metal-mechanic sector; brazil.

\footnotetext{
' Department of Industrial Engineering, Polytechnic School, University of São Paulo. Av. Prof. Luciano Gualberto, 530, Butantã, São Paulo, Brazil - 05508-010.e-mail: fflara@yahoo.com.br

${ }^{2}$ Departament of Industrial Engineer, Federal University of São Carlos. Rod. João Leme dos Santos (SP-264), Km I I0, Itinga, Sorocaba, Brazil - I8052-780.e-mail:mrng@ufscar.br
} 


\section{Introduction}

For many years the production function was restricted to the level of factory floor regardless of the strategic position it has in the organization. However, several authors (Hayes and Wheelwright, 1984; Hill 1989; Hayes and Pisano, 1994; Voss, 1995; Ward and Duray, 2000; Peña and Garrido, 2008; Peng et al., 20 I I; Choudhari et al., 20I2) assert the importance of manufacturing strategy in the organizational context.

According to Voss (1995), the production strategy is related to the policies and goals for using the resources of a company. Its content is determined by competitive priorities and the areas of structural and infrastructural decisions, which play a fundamental role in this process and must be aligned to the competitive strategy.

To Garrido et al. (20II) the competitive priorities in operations refer to the goals that companies should pursue in order to reinforce their competitive advantages. These competitive advantages are used to describe the operational choices for a particular functional area, which in turn constitute the expression of the company global competitive strategy.

If on one hand the competitive priorities play an important role in developing competitive advantages of a company, on the other hand innovation is being considered as a fundamental strategic factor for organization to develop competitive advantages. However, there is little research linking competitive priorities with innovation in the organizational context.

Several authors (Chiesa et al., 2000; Skilton and Dooley, 2002; Castellacci, 2008; Kaminski et al., 2008; Gibson and Naquin, 20II; Azadegan et al., 2013; Ota et al., 2013) have shown the importance of innovation for the competitiveness of companies. For Banerjee (2000), among the most important strategic factors involved in the current stage of global competitiveness are the capacities of organizations to absorb new technological knowledge for their products and for their respective processes.

Several factors influence the innovative behavior of an organization.Among these factors is its competitive strategy (Becheikh et al., 2006). In this way, if the competitive strategy exerts a strong influence in the innovative behavior as asserted by Becheikh et al. (2006) then the competitive priorities, that are part of the content of the production strategy, as stated by Voss (1995), also influence innovation. That is, innovation can be generated based on the competitive priorities adopted by companies.
Furthermore, the OECD (Organisation for Economic Cooperation and Development) (2005) recommends the identification of the economic reasons by which a company motivates itself to develop innovation activities and the goals that the innovation process can provide. These goals can be, among others, the replacement of products that are being discontinued; the increase of the product line; the development of environmental friendly products; the maintenance or the increase of the market share; the increase of the flexibility and quality and the reduction of the production costs.

Considering that innovation can lead to the practice of competitive priorities, this research aims to analyze the influence of competitive priorities in the practices and adoption of innovations considering the context of small businesses of the metal-mechanic sector of the Sorocaba area (State of São Paulo, Brazil).

According to SEBRAE (support service for micro and small enterprises - the official organ of the Brazilian government to support micro and small enterprises) (201I), micro and small businesses are responsible for more than half of formal employment in Brazil. If we add the jobs that the entrepreneurs create for themselves, micro and small businesses are responsible for at least two-thirds of the existing jobs in the private sector of the Brazilian economy.

The choice of the metal-mechanic sector to study is due to its relevance to the Sorocaba area. According to Amato Neto (2009), the Sorocaba area has an industrial park based on the metal-mechanic sector with machinery, equipments, automotive, and electrical industries. Small and medium enterprises supply support services and are considered important in the city area.

The paper is divided into five sections. The next Section presents the theoretical basis and the main concepts related to strategy in organizations (specially competitive priorities) and its relation to innovation. The third Section discusses the research method. The presentation and analysis of the research results are made in the fourth Section. The last Section concludes. 


\section{Literature review}

According to Mintzberg et al. (1998), strategy is the high point in the management activity and has been used and studied for a long time.

Hayes and Wheelwright (1984) define production strategies as a set of goals, policies, and restrictions defined and applied by the organization in order to plan, guide, and drive the invested resources to reach the goals and propitiate an effective implementation of the competitive strategy of the company. Wheelwright (1984) adds that there are three hierarchy levels for strategies.

The first level, called global or corporative strategy, covers market decision like how the organization organizes itself to reach some niches and how it allocates resources to the most important activities. The second level, the competitive strategy or business strategy, covers the way each business unit of the company looks for competitive advantage. The third level, functional strategy, supports the kind of competitive advantage that is looked for (Wheelwright, 1984).

This perspective, according to Hayes and Wheelwright (1984), describes strategy by means of hierarchical decisions and it is known as perspective top down of analysis. In the third level, functional strategy, establishes individual goals for each functional area (production, marketing, research and development, and so on) in such way that they reach the strategic objectives assigned to each business unit.

A usual way of visualizing production strategy, according to Voss (1995), is to separate the approach in two different terms. The first of them refers to the "process" of how these strategies are determined and rule the company procedures to produce specific decisions. The second one refers to the "content" of the strategy, which are the specific actions that constitute the points on which the decisions are taken. The content of a strategy involves the functional decision areas and the competitive priorities (Voss 1995).

Several authors (Hayes and Wheelwright, 1984; Kathuria, 2000; Grobler and Grubner, 2006; Miltenburg, 2008; Vachon et al., 2009) have appointed four main competitive priorities: cost, delivery, flexibility, and quality. Christiansen et al. (2003) and Ward et al. (2007) corroborate these four generic priorities based in international publications. However, Christiansen et al. (2003) point that, although there is a high degree of agreement in the studies that cost, delivery, flexibility, and quality are important competitive priorities, there is a series of debates about additional priorities and the concepts involved in each one of them.
Besides that, some authors autores (Dangayach and Deshmukn, 2000; 2006; Rob and Xie, 200I; Rusjan, 2005; Theodorou and Florou, 2008; Radas et al., 2009) insert innovation as one of the competitive priorities and/or as central element for the acquisition of competitive advantages. Although such authors consider innovation as a competitive priority, their approach to innovation is near to the concepts used by Oke (2005) for flexibility. This author analyzes flexibility from four perspectives:

- flexibility of new products: capacity of introducing and produce new products or modify those already existing;

- mix flexibility: capacity of change the range of products that are being made by the production system in a determined time period;

- volume flexibility: capacity of changing the aggregate production level;

- delivery flexibility: capacity of changing the planned or assumed delivery deadlines (Oke, 2005).

Dangayach and Deshmukh (2000; 2006), Rob and Xie (200I) and Theodorou and Florou (2008) place innovation as the capacity of introducing new products (mainly) and of new processes. Besides that, Theodorou and Florou (2008) relate the frequency of innovations with the frequency of changes in the product design and Rob and Xie (200I) consider innovation as synonymous to the capacity of creating variations of existing products, facts that are also related to the flexibility of production mix described by Oke (2005).

Georgsdottir and Getz (2004) define flexibility as the capacity to change which is caused either by a pressure to adapt to a challenging environment (adaptive flexibility) and a spontaneous preference to change. The authors consider flexibility as a primordial characteristic of innovative companies and that companies with a high level of flexibility are, generally, the most innovative.

On the other side, there are authors (Burgess et al., 1998; Becheikh et al., 2006; Weerawardena and Mavondo, 20I I; Gunduz and Semercioz, 20I2) that analyze the influence exerted by the adopted strategies by companies in the creation of innovation. Weerawardena and Mavondo (20l I), for example, assert that in the last decade the vision based on capabilities obtained by means of competitive strategy emerged as a theoretical framework to heterogeneity in the different performance levels of companies. 
According to some authors autores (Skinner, 1969; Burgess et al., 1998; Garrido et al., 20II) generally competitive priorities indicate which performance areas should be emphasized to guarantee the competitive success of a company. Once the priorities are defined, they should be applied considering the competitive environment in which the company is: if innovation is a central element in the production strategy, the competitive priorities should be pursued in order to beat the competitors by means of new forms of their elaborations (Wheelwright and Bowen, 1996). So, individually companies strive to improve their performance in the competitive priorities in several ways. As a consequence, they take measures to improve the competitive performance through the adoption of innovations as, for example, process innovation, total quality management and/or simultaneous engineering (Burgess et al., 1998).

To Burgess et al. (1998), cost has already been considered the great competitive priority. However, there is a tendency in pointing quality and flexibility, more and more, as primordial aspects to the future.

Becheikh et al. (2006) agree with these authors when they show the positive effect that innovation exerts on flexibility. If a company intends to be innovative, even if takes centralized measures for decision taking, it should assure that its structure is kept flexible and that communication and knowledge coordination are stimulated. Furthermore, the preoccupation in reducting factory costs by specialization and volume has been shown to be a disincentive to innovation (Becheikh et al., 2006).

This research follows the OECD (Organisation for Economic Co-operation and Development) (2005) classification to innovation. Four kinds of innovation are considered:

- product innovation: a new good or service or goods or services substantially improved in relation to their characteristics or foreseen uses;

- process innovation: the implementation of a new production method or distribution or the implementation of a substantially improved process;

- marketing innovation: a new method with significant changes in the empreendimento product, in its positioning, in its promotion or pricing;

- organizational innovation: the introduction of a new organizational method which may be business practices in the organization, in the work place, or in the external relationships. This method should not have been used previously (OECD, 2005).
According to Becheikh et al. (2006), innovation in the industrial sector is a complex process, driven by numerous factors once that, besides a significant number of explanatory variables, these same variables are moderated by interaction with other determinant variables, whether internal or external to the company.

To Raymond and St-Pierre (2010) innovation has been regarded as the key factor for survival, growth, and development of small businesses, thus becoming an important way these companies continually seize new opportunities to sustain a competitive advantage.As the ability to develop new products and innovate is at the core of value creation, small businesses must continuously improve their manufacturing processes in order to ensure its long-term survival.

Begin the introduction here. Retype your title and center it at the top of the introduction as indicated above. Notice that these paragraphs should have a normal (.5 inch) indent. The main purpose of this section is to tell the reader why you performed the study. In other words, you have to inform the reader of the research question and indicate why it is important, and how it is unique when compared to previous studies. It starts out broad and becomes more and more specific. For example, you might begin by defining any relevant terms. Then go on to review the relevant literature. Avoid an exhaustive and historical review. Then go on to make clear the connection between previous research and the present work. You might include any hypotheses and the rationale for them. The final paragraph usually contains a statement which clearly and explicitly states why the study was performed.Thus, this section should contain an absolute minimum of four paragraphs: the general introduction, the literature review, the connection of the present study to the literature and the explicit statement of purpose.

\section{Method}

The method of case study is appropriate (Eisenhardt, 1989; Yin, 2003) because the research goal is to investigate an emergent phenomenon over which the researcher has no control; that is, the influence of the competitive priorities in the generation of innovations in small companies of the Brazilian metal-mechanic sector. To Choudhari et al. (20I2), the fundamental goal of a research that uses case studies is to decrease the distance between theory and practice, making the research useful for practitioners. 


\section{Procedures for case selection}

According to Yin (2003), there is no consensus on the ideal number of companies in a case study: a single case or multiple cases. The adoption of a single case suffers the limitations related to external validity because the research generalization can lead to misguided conclusions.

On the other side, multiple cases may result in a greater reliability in the generalizations but with less depth and a greater execution time than a single case. There is a consensus that in multiple-case studies, the recommended number should be between four and ten companies (Eisenhardt, 1989; Yin, 2003).
The researched companies were selected based on the public database of the Sorocaba regional office of FIESP (Industry Federation of the State of São Paulo).The number of six companies was chosen based on the time availability of the researches for visits and analysis of the data gathered. The criteria adopted to consider a company as "small" is the same as that used by SEBRAE (20II); that is, those that have between 20 and 99 employees. The phone contacts were made primarily to the owners and, in the absence of these, to the production managers.

Broadly, companies A and B operate as equipment manufactures. Companies $C$ and $D$ are service supplies of machining to third parties by means of partnership to a great client in their niches of operation. Companies $\mathrm{E}$ and $\mathrm{F}$ operate as valve supplies to several segments, mainly that of Oil and gas.

Table I synthesizes the main characteristics of the analyzes companies.

\begin{tabular}{|c|c|c|c|c|c|c|}
\hline \multirow{2}{*}{$\begin{array}{l}\text { General company } \\
\text { characteristics }\end{array}$} & \multicolumn{6}{|l|}{ Company } \\
\hline & $A$ & B & $C$ & $\mathrm{D}$ & $E$ & $\mathrm{~F}$ \\
\hline Age (years) & 18 & 30 & 10 & 8 & 17 & 25 \\
\hline Number of owners & 1 & 2 & I & 1 & 1 & 1 \\
\hline Total de funcionários & 75 & 30 & 48 & 22 & 36 & 72 \\
\hline Capital origin & I00\% brazilian & I00\% brazilian & I00\% brazilian & I00\% brazilian & I00\% brazilian & I00\% brazilian \\
\hline $\begin{array}{l}\text { Main area of opera- } \\
\text { tion }\end{array}$ & equipaments & equipaments & $\begin{array}{l}\text { services pro- } \\
\text { vider (machines) }\end{array}$ & $\begin{array}{l}\text { services pro- } \\
\text { vider (machines) }\end{array}$ & valves & valves \\
\hline Main products & $\begin{array}{l}\text { equipments for } \\
\text { drying ceramics }\end{array}$ & $\begin{array}{l}\text { term-accumula- } \\
\text { tion tanks and } \\
\text { pressure vessels }\end{array}$ & $\begin{array}{l}\text { machining ser- } \\
\text { vices for third } \\
\text { parties with } \\
\text { focus in heavy } \\
\text { machining }\end{array}$ & $\begin{array}{l}\text { machining ser- } \\
\text { vices, assembly, } \\
\text { and technical as- } \\
\text { sistence to third } \\
\text { parties }\end{array}$ & $\begin{array}{l}\text { orifice plates, } \\
\text { flow meters, } \\
\text { and valves for } \\
\text { instrumentation }\end{array}$ & $\begin{array}{l}\text { orifice plates, } \\
\text { flow meters, } \\
\text { and valves for } \\
\text { instrumentation }\end{array}$ \\
\hline Interviewee & $\begin{array}{l}\text { Production } \\
\text { Manager }\end{array}$ & $\begin{array}{l}\text { Production } \\
\text { Manager }\end{array}$ & $\begin{array}{l}\text { Owner and } \\
\text { Production } \\
\text { Manager }\end{array}$ & Owner & $\begin{array}{l}\text { Production } \\
\text { Manager }\end{array}$ & $\begin{array}{l}\text { Production } \\
\text { Manager }\end{array}$ \\
\hline
\end{tabular}

Table I. General characteristics of the surveyed companies.

ISSN: 07I 8-2724. (http://www.jotmi.org) 


\section{Case Protocol}

In this way, the research protocol nucleuses are the questions that are used in the interviews. In case study strategies, a research protocol should contain the research main question, main goal, theoretical supporting themes, definition of the unit of analysis, potential interviewees, realization period, site of evidence gathering, and interview guide synthesis (Voss et al., 2002).

According to Yin (2003), the protocol of the case is a necessary tool when conducting multiple case studies. Voss et al. (2002) point out that scientific research should include procedures and general rules that should be used in the process of collecting data and evidence, indicate who or where the information can be collected. Table 2 synthetizes the research protocol.

It is emphasized that, in the issues dealing with the occurrence of innovations, the period of last five years to conduct the study was used to allow comparison between the studied companies. In addition, we adopted the technique of observation in order to enhance the quality of search results.

\section{Validity and reliability}

According to Yin (2003), it is very important to the quality of a research involving case studies to verify the validity and reliability of the construct. The construct validity is achieved through the chaining and the use of multiple sources of evidence and a review of the case report by respondents (Yin, 2003). These actions were performed during the step of collecting and analyzing data. As noted above, the results obtained by conducting semi-structured interviews were confronted and complemented with information gathered by the use of the technique of observation.

Furthermore, Yin (2003) recommends attention to internal and external validity of the research. For the internal one, the researcher should test the internal consistency between the initial propositions, development, and results. For this, the used literature focused the relationship of the influence exerted by the competitive priorities in the practice and adoption of innovations. For external validity, i.e. the degree to which the research is generalizable (Yin, 2003), although multiple cases have been made, it is not considered possible to generalize this study, given the heterogeneity of the companies of the analyzed sector. Reliability relates to the possibility of replication of the research. It is guaranteed in the data collection phase and the protocol is very important to guarantee it.

\begin{tabular}{|c|c|}
\hline Contents & Addressed form \\
\hline Research goals & $\begin{array}{l}\text { Analyze the influence exerted by competitive priorities in the practice and adop- } \\
\text { tion of innovation }\end{array}$ \\
\hline Theoretical support & $\begin{array}{l}\text { Innovations (product, process, marketing, organizational) in function of competi- } \\
\text { tive priorities (cost, delivery, flexibility, quality) employed in the companies }\end{array}$ \\
\hline Unit of analysis & Production department of small companies of the metal-mechanic sector \\
\hline Potential interviewees & Owner or production manager \\
\hline Collection site & Factory \\
\hline Collection period & Between April and May 2012 \\
\hline \multicolumn{2}{|c|}{$\begin{array}{l}\text { Although the four competitive priorities are stimulated and practiced in company, which are the most important in } \\
\text { this case? }\end{array}$} \\
\hline \multirow{3}{*}{\multicolumn{2}{|c|}{$\begin{array}{l}\text { In the last five year was there any release of a new product or a substantial improvement of an existing product? } \\
\text { In the last five years was there a release of a new process or a substantial improvement of an existing process? } \\
\text { In the last five years was there the implantation of a new business model? Was there any changing in the way knowl- } \\
\text { edge is shared or learned inside the company? }\end{array}$}} \\
\hline & \\
\hline & \\
\hline \multicolumn{2}{|c|}{$\begin{array}{l}\text { In the last five years was there the implementation of some new marketing method involving substantial improve- } \\
\text { ments in the design of a product or packing, price, distribution, and promotion? }\end{array}$} \\
\hline \multicolumn{2}{|c|}{ How much the competitive priorities of the company influenced in the cited innovations? } \\
\hline
\end{tabular}

Table 2. Case Protocol.

ISSN: 07 I8-2724. (http://www.jotmi.org)

Journal of Technology Management \& Innovation (c) Universidad Alberto Hurtado, Facultad de Economía y Negocios. 


\section{Data collection and tabulation}

The analysis stage of the data is the most difficult step and also one of the most important in the case study (Eisenhardt, 1989). The data analysis was based on the premise of Eisenhardt (1989) that the cases should be analyzed in several divergent ways. One approach is to select categories or dimensions after looking at the similarities among groups along with the differences between the same groups.

To analyze the evidences for the presence of innovation in the surveyed companies in the light of competing priorities we conducted narrative interviews which were recorded. These recordings were fully transcribed shortly after being made. Moreover, this information was supplemented by additional information given by the respondents on a accompanied visit to the production process and by notes made in a field diary containing information obtained through observations. With the transcription of data it was possible to select categories according to the type of innovation (product, process, marketing, organizational) and based on these categories it was analyzed the influences of the competitive priorities (cost, delivery, flexibility, quality) selected for the study.

\section{Case analysis and discussions}

The presentation of the results is divided into six subtopics. The first presents the identification of competitive priorities in the studied companies. The following four subtopics present a discussion of the influence exerted by these priorities in generating innovation according to the classification of the OECD (2005): product innovation, process, organizational and marketing. Finally, it is presented a final subtopic consolidating the results.

\section{Competitive priorities of the surveyed companies}

For the identification of competitive priorities, the companies were asked about which of cost, delivery, flexibility, and quality would be the decisive criterion for the company. Other used criterion for the identification of priorities practiced in the companies were the perceptions of the researchers during the case studies. The competitive priorities identified were:

a) to company $A$ : quality, delivery, flexibility;

b) to company B: flexibility;

c) to company C: quality;

d) to company D: cost, quality;

e) to company E: cost;

f) to company F: quality, cost.

\section{Product Innovation}

The same companies were also responsible for substantial improvements in their products. In the case of companies $B$ and $E$, the improvements were in order to significantly change the existing design to meet new market demands. To company $F$, improvements were suggested by the field technicians in order to improve the quality of the product applied at the client.

With respect to product innovation, only companies B, E and $F$ have launched at least one new product in the last five years. Companies $E$ and $F$ were driven by the specific demands of Petrobras (Petróleo Brasileiro - it is a corporation whose majority shareholder is the Government of Brazil. It is one of the leading and largest companies in the country). Company $B$, using its existing structure, has developed new products for its own initiative in order to conquer new markets. In the three companies, products have been developed primarily by the company itself.

None of the companies has generated patents to date. Although the new or modified products are innovative to the company, they are not innovative to the market. However, company $\mathrm{E}$ is currently developing a specific valve for the automotive industry, which will generate a patent and it will allow the start of a serial production.

There was a heterogeneity in the responses to the question "In which degree product innovation or substantial improvements in the existing products was the result of the competitive priorities?".

Company A did not relate any competitive priority to the activity of product innovation in the company. There is a demand of their customers for products with better quality, however, the company has not generated any product innovation from this competitive priority.

Company B points to flexibility as the impetus to product innovation, especially to suit the demands of clients. Products like compressors, compressed air systems, and dive equipments already existed in the company, but it was necessary to change their design to meet new demands and keep existing customers.

Companies $C$ and $D$ do not have their own products because of the type of market in which they operate.

Companies $E$ and $F$ operate in the same market, but responded differently to the survey. And although the company $E$ has mentioned cost, the only factor actually observed was flexibility. Company $\mathrm{F}$ pointed quality as an element to boost innovation activity in the company. 
To company $E$, the determining factor is the need of the client. The company avoids working with trial and error not to generate unnecessary costs. However, states seek to develop their innovations as specific customer demands in order to keep them in their sales portfolio.

Company $\mathrm{F}$ pointed quality, meaning to produce products with features and functionalities that are superior to competitors and with low defect rate, as encouraging innovation of products. There were no formal complaints from customers about the quality of the products. However, indications from field workers of the company give rise to researches to improve some products as, for example, orifice plates. In this case, there was substantial improvement of the product.

Thus, when we verify the influences exerted by competitive priorities in generating product innovation, we can see that flexibility exerted influences in companies $B$ and $E$ and quality in company $\mathrm{F}$.

Both companies $B$ and $F$ argued that flexibility was required in order to change the design to meet new market demands and keep their customers in backlog. When conducting field work, the maintenance technicians of company $\mathrm{F}$ realized the need to improve product quality and directed efforts to substantial improvements in the product. In this particular case, it was a measurement probe. Figure I consolidates the results.

\section{Process Innovation}

All companies studied presented some degree of innovation, be it by a new process or a substantial improvement of an existing one. Process innovations that occurred in the surveyed companies are a method of manufacture or production of goods and have been developed exclusively for the company.
To company B, and only for it, process innovation did not require great investments in equipments but it required greater technical demands from their employees, with the introduction of submerged arc welding system.

It is important to stress that no new products boosted the innovation of processes. However, for company C, the acquisition of new equipment allowed its entrance into the heavy machining segment. According to the company, it was necessary to make considerable investments in equipment and training in order to adapt to this new market.

Companies $A$ and $D$ have perfected the methods of internal logistics with the insertion of new forms of material handling. Company B, although it has not acquired new equipments, developed a new internal process to paint the inside of welded parts, so as to protect from rust the inner part of the equipment. This was a requirement of Petrobras to keep company B as a supplier. This measure aims to meet safety standards and to ensure the protection of employees in field activities.

Companies $A$ and $D$ showed significant improvements with the new methods of internal logistics. Company $A$ points out that prior to these changes, there were five employees and the deadlines were often not met. Today there are three workers, with deadlines on time.

Just as in the case of product innovation, the responses varied from company to company to the question whether the process innovation or substantial improvements in the existent processes were caused by the competitive priorities of the company.

Company A stated that substantial process improvements occurred to minimize the delivery time to their customers, until then the big problem of the company.

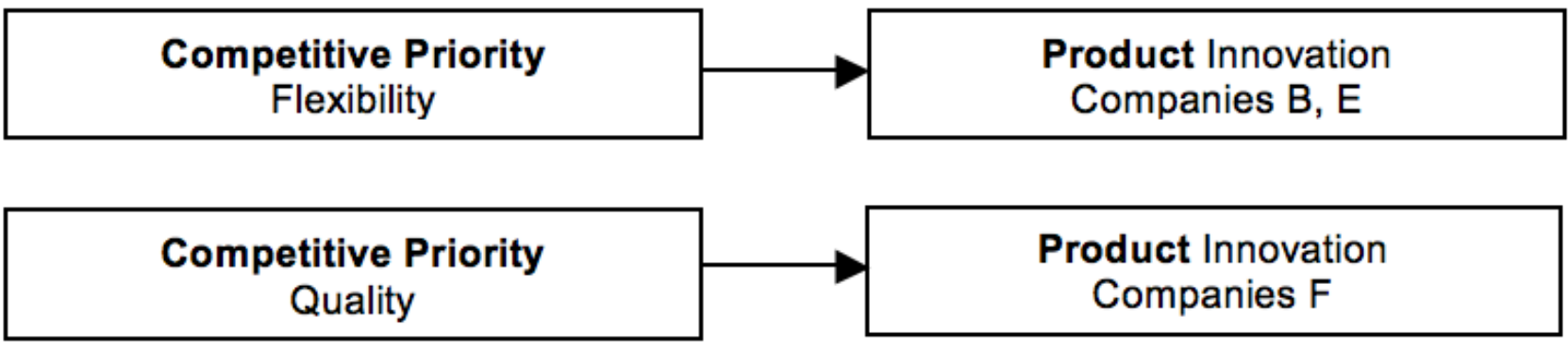

Figure I. Competitive priorities as support for product innovation. 
In the same way as observed for product innovation, company B answered that substantial improvements in their process were to ensure the flexibility of service and the ability to execute the projects demanded by customers within the required quality standard.

Company C, although it argued that cost and delivery are critical, quality was listed as the major stimulus for the acquisition of new equipment with different functions from the existing ones. With this, the company gained in productivity, quality and compliance with the required technical specifications, which enabled its entrance in the niche market of heavy machining.

Company $D$, in turn, stated that the priority delivery was responsible for substantial improvements made in its internal logistics materials. Through the new factory settings the company was able to lower its process time and hence respond more quickly its customers.

Company $\mathrm{E}$ pointed cost as the main element in fostering process innovation. Once that the most representative element for the company in the composition of spending requests is the raw material, to improve the process was pointed as the solution to optimize resources and lower the cost. There is an ongoing project to insert the company in the automotive industry, which will only be feasible if the company develop mechanisms to reduce costs, both from materials and processes in relation to what is currently practiced.
Finally, Company $\mathrm{F}$ also raised the issue of the cost as the most important. The process reformulations were implemented to decrease production time and promote greater competitiveness in the final price with the Chinese market. With new equipment, the company went on to compete in the market in terms of price again.

Thus, in relation to the influences of competitive priorities in the generation of process innovation, the four priorities studied exerted some kind of influence on the generation of innovation. Figure 2 consolidates the results.

\section{Organizational Innovation}

Only company A did not developed or has no interest in developing a new business model. Other companies have this concern and it was appointed the importance of efforts for this to take effect.

Company B has a project whose goal it to develop a hyperbaric clinic linked to the medical field, which will mean the company's entry into a business segment completely different to the current activities related to the area of metalworking.
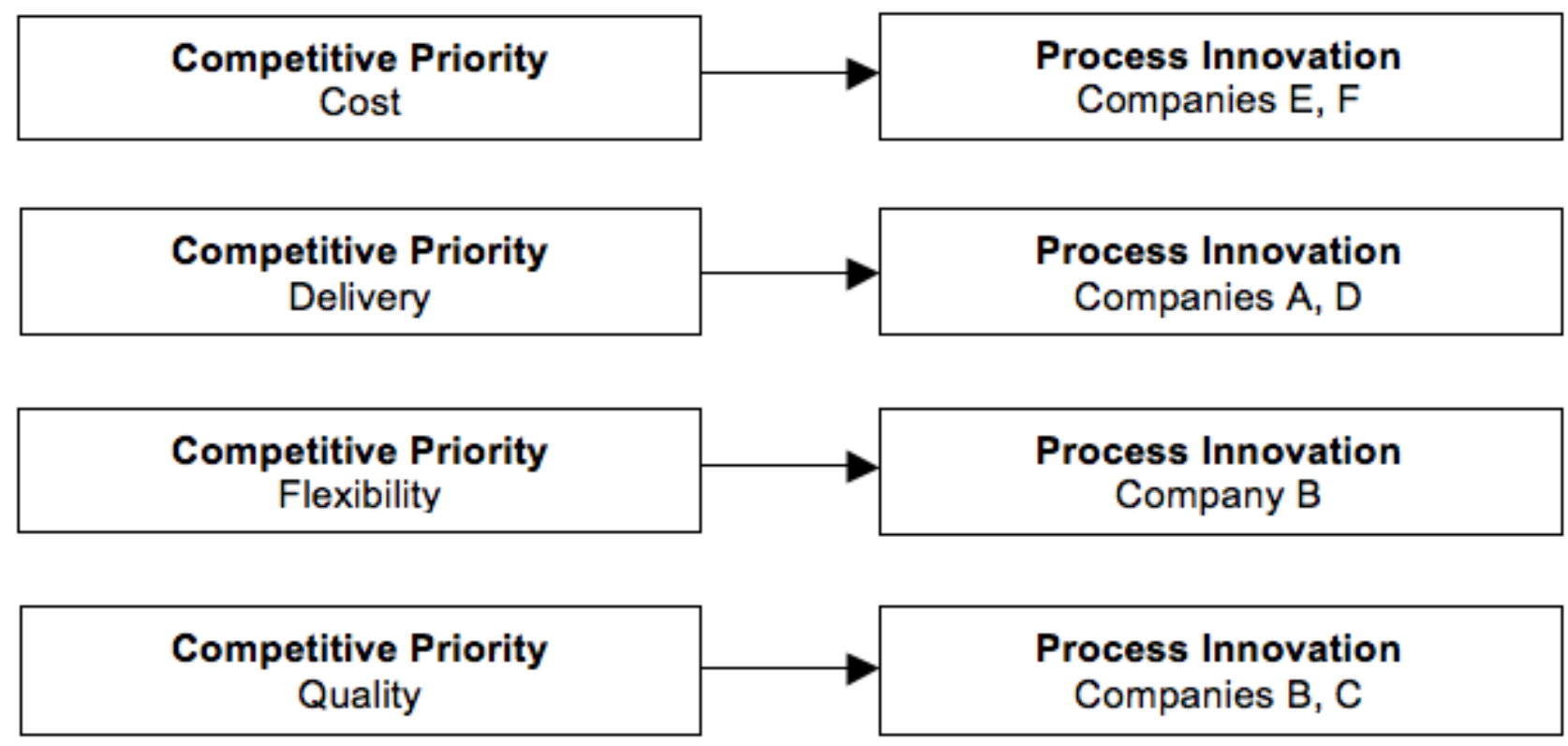

Figure 2. Competitive priorities as support for process innovation.

ISSN: 07 I8-2724. (http://www.jotmi.org)

Journal of Technology Management \& Innovation (c) Universidad Alberto Hurtado, Facultad de Economía y Negocios. 
Companies $C$ and $D$ have argued that by not having your own product, they need to constantly develop new business according to market fluctuations. Company $\mathrm{C}$ demands mainly trained manpower in work other than machining. This company have entered the heavy machining segment, consuming large efforts in terms of investment and training. It is starting its insertion in providing boiler services, although linked to the activities of the metalworking industry. Company D, in turn, is starting to provide technical assistance in the equipments it manufactures for its main customer. Currently, the company is the largest specialist in bandsaw machines in Latin America and it has created a new mode of service delivery due to this specialty.

Company $E$ is in the development phase of a project to support, pioneer in serial form, the automotive industry. According to the company, if the project is confirmed there will be significant changes to the business of the company, particularly in terms of investment in equipment, certifications, and training for plant staff.

Company $F$ will start a new way of realizing labor for special projects. According to the company, some demands with deadlines are common and, as a way of trying to balance the hiring and firing of employees on the basis of these oscillations, the company will resort to ad hoc teams. The profit of each project will decrease. But the lower expenditure on labor will compensate this lower profit.
In relation to the question "are the organizational innovations a result from the competitive priorities of the company?", we could see a similarity in the responses depending on the characteristics of the market in which they operate.

Companies A and B pointed out that organizational innovations or substantial improvements that occurred in their organization's work had the ultimate goal of improving delivery times, which may be between internal process steps or to the customer.

Companies C and D stressed the issue of quality of customer service. They noted that, when a company has different clients, there is a need to adapt to the way of working of each of them. This fact generates dynamism and impact on the organization work of the company. In a very similar way, companies $E$ and $F$ said that the primordial objective is to reduce costs be it by reducing the flow of information, materials, or by decreasing the margin of error in manufacturing. This is necessary because the profit margins are low in valve manufacturing industry. Figure 3 consolidates the results we got.
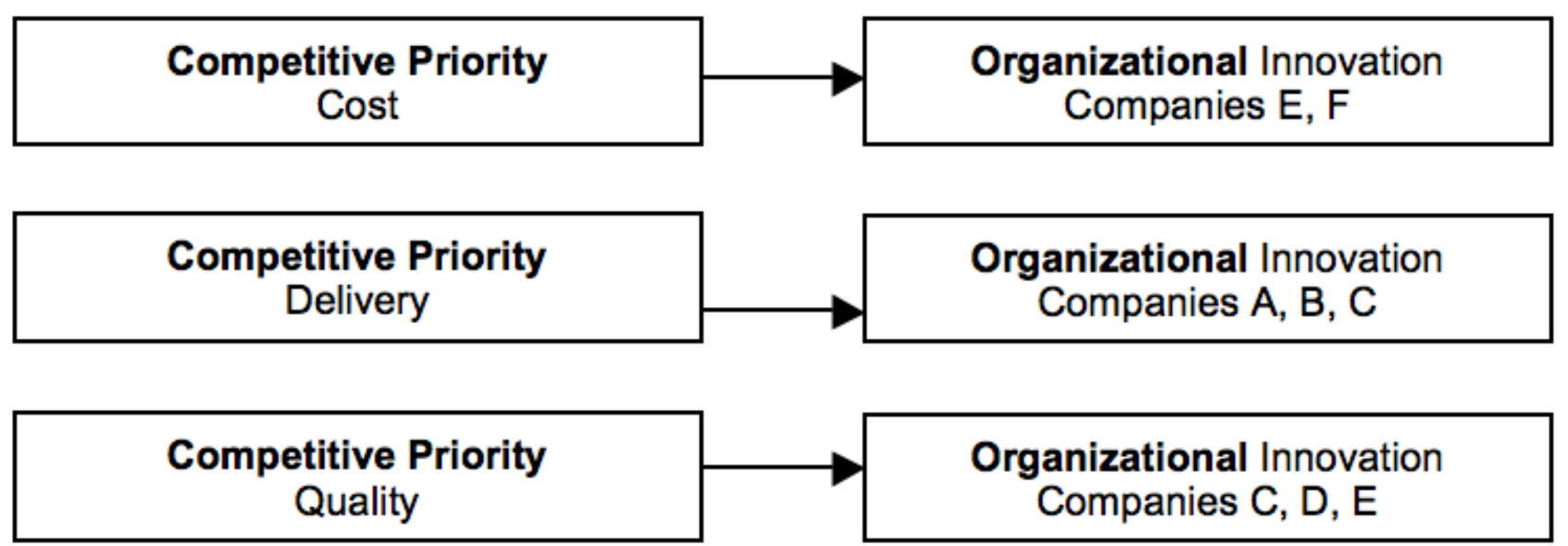

Figure 3. Competitive priorities as support for organizational innovation.

ISSN: 07 I8-2724. (http://www.jotmi.org) 


\section{Marketing Innovation}

Regarding the implementation of new marketing method, we verified that, except in Company F, little has been done in order to get significant improvements or innovations in product design, packaging, promotions, or new sales platforms. Companies A and D have made some specific actions such as the creation of a promotional video and a site, respectively. Although both were satisfied with the results, neither company made a specific plan for marketing or planed new actions for next year.

Companies B and E pointed out that, in recent years, they invested heavily in product, processes, and training of their employees. Thus, they asserted that they have reached a certain level considered interesting to, in the next few years, intensify their investments with focus on marketing. Company $\mathrm{E}$ said that, in the subsequent year this survey was made, the focus will be on marketing and in the search for new customers.

Company $C$ changed the way of presenting the product to their customers, developing new packaging with label and company logo. According to the response, the aim was to promote the concept of quality that the company invests (there was no demand from its customers for this).
Company $F$, in turn, has sought to create new ways of promoting their products and a closer relationship with its customers. The company has adopted a policy, in the past three years, of starting their new product testing as a way to show, improve and disclose them in the sector in which the company intends to invest its efforts.

Finally, with regard to innovations in marketing as a result of competitive priorities, all companies but $A$ and $B$ pointed out the influence of at least one of the priorities as support for innovation in this context.

Company $\mathrm{C}$ believes that it has developed a new packaging driven by competitive priority quality. According to the response, the client required something simple, however, the company chose to make something sturdy, sending the message that the service provided by the company "is great and not good."

Companies $\mathrm{D}$ and $\mathrm{E}$ also stated that with innovations and investments in marketing, it is possible to increase the number of requests. With this, the company's costs can be spread over more customers, improving results and enabling new investments. From this perception the companies invested in preparing the company's website.

Company $\mathrm{F}$ also pointed out the issue of increased sales as a key driver. However, the company claims that the issue of quality of its products was key to the beginning of a dynamic of pilot tests of new products in partnership with clients, in order to seek control all contingencies before initiating an effective sales campaign. Figure 4 consolidates the results.
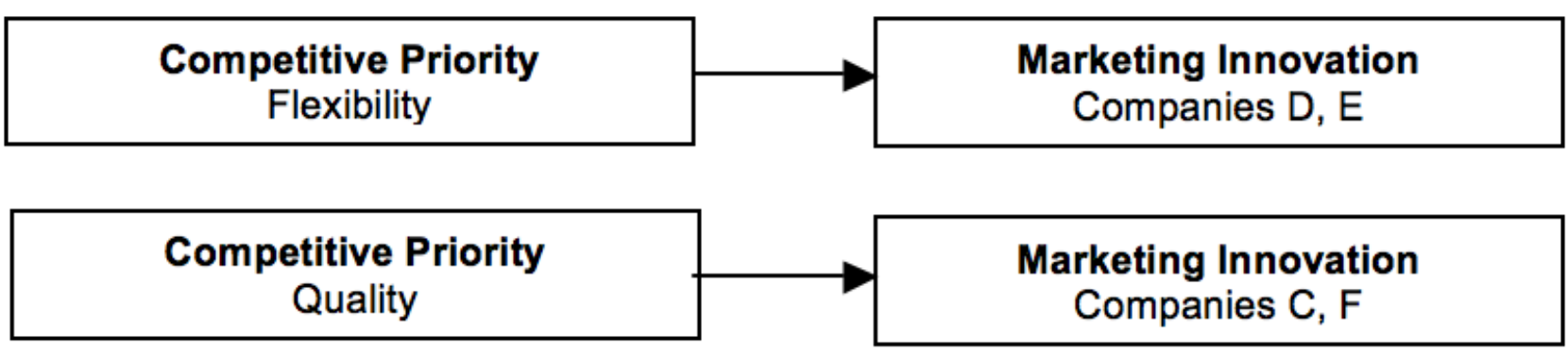

Figure 4. Competitive priorities as support for marketing innovation. 


\section{Consolidated results}

Based on the results presented in the previous four subtopics, it was found that the quality, flexibility, delivery and cost are, in that order of importance, generators of innovation practices in the surveyed companies. Figure 5 consolidates the results.

In the surveyed companies, quality and flexibility are intimately related to technological product innovations and process. In the non-technological innovations, quality influenced the marketing and organizational innovations. It may be noted flexibility as generating marketing innovations and cost and delivery as factors that led to organizational innovation.

\section{Conclusions}

The results contribute to the understanding of the relationship between two distinct themes Production and Innovation Strategy, though tending to be interrelated. With the survey results, it was verified how is the support relationship from one to the other according to the initial proposal.Thus, we obtain evidence for future public policies to stimulate innovation in small firms, a subject of academic and commercial importance.

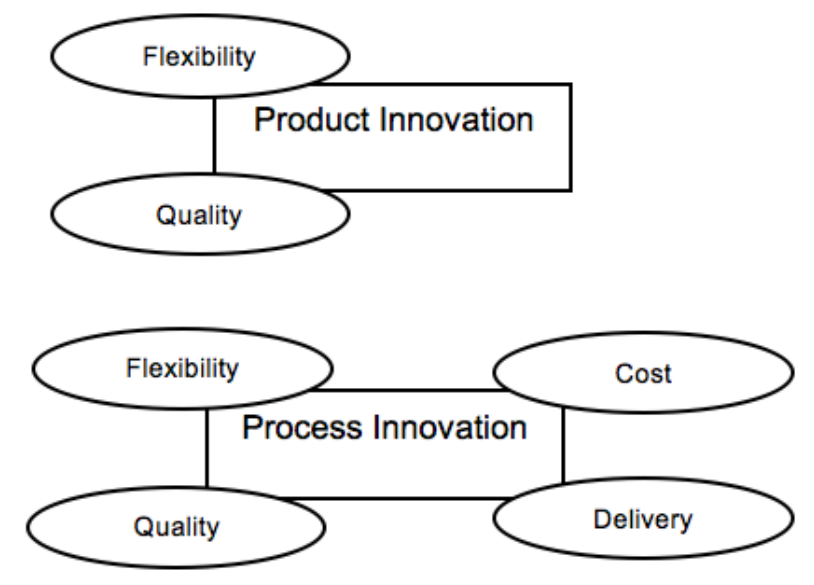

This research shows that innovation is not only done with financial investments, a result still little explored in the literature. As noted in some of the companies studied, the strategic reorganization and rationalization of production resources through competitive priorities can lead to innovation in different spheres. This helps to increase the competitiveness of enterprises and to strengthen the national economy. Moreover, a better understanding of the context of small businesses, given their greater weakness in injection of capital, contributes to new perspectives for better development and strengthening at both the national and international scenario for these companies.

It is understood that this work is not amenable to generalization, given the number of cases studied and the heterogeneity of the companies that make up what is called in this work metalworking industry. However, the "clues" obtained in this research can be used in future works and the limitations presented at this time may be reconsidered in future research. Some possibilities would be: to analyze the relationship between competitive priorities and innovation in a set of companies that operate in the same business, allowing a better comparison between companies; to examine the influence of the characteristics of small business in the practice of innovation through a survey covering a large number of companies.
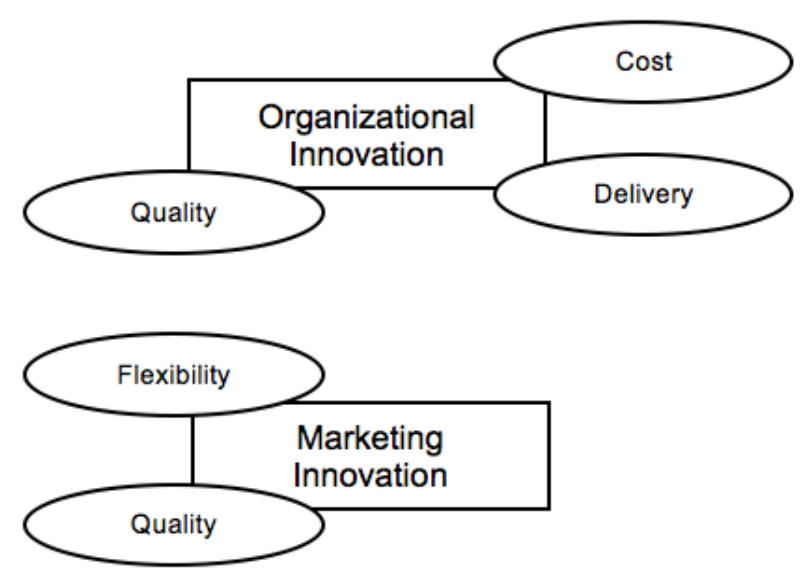

Figure 5. Overview of influence received by innovation in the surveyed companies.

ISSN: 07 I8-2724. (http://www.jotmi.org) 


\section{References}

AMATO Neto, J. (2009). Gestão de Sistemas Locais de Produção e Inovação (Clusters/APLs), Atlas, São Paulo.

AZADEGAN,A., Napshin, S. and Oke,A. (20I3).The influence of R\&D partnerships on innovation in manufacturing firms: The moderating role of institutional attachment. International Journal of Operations and Production Management, 33(3), 248-274. DOI: |0. I |08/0 |44357| 3 | | 300755.

BANERJEE, S. K. (2000). Developing manufacturing management strategies: influence of technology and other issues. International Journal of Production Economics, 64( I3), 79-90. DOI: 10.1016/s0925-5273(99)00046-8.

BECHEIKH, N., Landry, R. and Amara, N. (2006). Lessons from innovation empirical studies in the manufacturing sector: a systematic review of the literature from 19932003. Technovation, 26(5-6), 644-664. DOI: 10.1016/j. technovation.2005.06.016.

BURGESS, T. F., Gules, H. K., Gupta, J. N. D. and Tekin, M. (1998). Competitive priorities, process innovations and time-based competition in the manufacturing sectors of industrialising economies: the case of Turkey. Benchmarking for Quality Management and Technology, 5(4), 304-3 I6. DOI: I0.1 I08/I46357798/0244478.

CASTELLACCI,F.(2008). Innovation and the competitiveness of industries: comparing the mainstream and the evolutionary approaches. Technological Forecasting and Social Change, 75(7), 984-I006. DOI: 10.10 I6/j.techfore.2007.09.002.

CHIESA, V., Manzini, R. and Tecilla, F. (2000). Selecting sourcing strategies for technological innovation: an empirical case study. International Journal of Operations and Production Management, 20(9), 1017-1037. DOI: 10.1108/01443570010339127

CHOUDHARI, S. C., Adil, G. K. and Ananthakumar, U. (20I2). Exploratory case studies on manufacturing decision areas in the job production system. International Journal of Operations and Production Management, 32(II), I337|36|. DOI: | 0. | | 08/0 |44357 | 2 | 274576.

CHRISTIANSEN, T., Berry, W. L., Bruun, P. and Ward, P. (2003). A mapping of competitive priorities, manufacturing practices, and operational performance in groups of Danish manufacturing companies. International Journal of Operations and Production Management, 23(10), 1163I |83. DOI: |0.1 |08/0|4435703104966|6.
DANGAYACH, G. and Deshmukh, S. (2000). Manufacturing strategy: experiences from select Indian organization. Journal of Manufacturing Systems, 19(2), I34-I48. DOI: 10.1016/ s0278-6I25(00)80006-0.

DANGAYACH, G. and Deshmukh, S. (2006). An exploratory study of manufacturing strategy practices of machinery manufacturing companies in India. Omega, 34(3), 254-273. DOI: 10.1016/j.omega.2004.10.009.

DÍAZ-GARRIDO, E., Martín-Peña, M. L., and SánchezLópez, J. M. (20II). Competitive priorities in operations: Development of an indicator of strategic position. CIRP Journal of Manufacturing Science and Technology, 4(I), I I8125. DOI:10.1016/j.cirpj.201 I.02.004.

EISENHARDT, K. M. (1989). Building theories from case study researches. Academy of Management Review, 14(4), 532-550. DOI: 10.5465/amr. 1989.4308385.

GEORGSDOTTIR, A. S. and Getz, I. (2004). How flexibility facilitates innovation and ways to manage it in organizations. Creativity and Innovation Management, I3(3), I66- I75. DOI: 10.1 III/j.0963-1690.2004.00306.x.

GIBSON, D.V. and Naquin, H. (20I I). Investing in innovation to enable global competitiveness: the case of Portugal. Technological Forecasting and Social Change, 78(8), 1299|309. DOI: 10.1016/j.techfore.201 I.04.004.

GRÖBLER, A. and Grübner, A. (2006). An empirical model of the relationships between manufacturing capabilities. International Journal of Operations and Production Management, 26(5), 458-485. DOI: 10.1 108/0|443570610659865.

GUNDUZ, E. and Semercisz, F. (20I2). The relation between competitive tension and strategic innovation. Procedia: Social and Behavioral Sciences, 58, 29-39. DOI: 10.1016/j. sbspro.2012.09.975.

HAYES, R. H. and Pisano, G. P. (1994). Beyond world-class: the new manufacturing strategy. Harvard Business Review, 72(10), 77-86.

HAYES, R. and Wheelwright, S. C. (1984). Restoring our competitive edge: competing through manufacturing, The Free Press, New York.

HILL,T.(1989). Manufacturing strategy, McGraw-Hill, London. 
KAMINSKI, P. C., Oliveira, A. C. and Lopes, T. M. (2008). Knowledge transfer in product development processes: A case study in small and medium enterprises (SMEs) of the metal-mechanic sector from São Paulo, Brazil. Technovation, 28(I-2), 29-36. DOI: I0.10I6/j.technovation.2007.07.00I.

KATHURIA, R. (2000). Competitive priorities and managerial performance: a taxonomy of small manufacturers. Journal of Operations Management, 18(6), 627-64I. DOI: 10.1016/ s0272-6963(00)00042-5.

MARTIN-Peña,M.L.and Díaz-Garrido,E.(2008)A taxonomy of manufacturing strategies in Spanish companies. International Journal of Operations and Production Management, 28(5), 455-477. DOI: I0.1 108/0 I4435708I0867204.

MILTENBURG,J. (2008). Setting manufacturing strategy for a factory-within-a-factory. International Journal of Production Economics, I I3(I), 307-323. DOI: I0.1016/j.ijpe.2007.09.00I.

MINTZBERG, H., Ahlstrand, B. and Lampel, J. (1998). Strategy safari: a guided tour through the wilds of strategic management, The Free Press, New York.

OECD (2005). Oslo Manual: Proposed guidelines for collecting and interpreting technological innovation data, 3 ed., Paris.

OKE, A. (2005). A framework for analysing manufacturing flexibility. International Journal of Operations and Production Management, 25(10), 973-996. DOI: I0.I I08/0| 4435705I06| 9482.

OTA, M., Hazama, Y. and Samson, D. (2013). Japanese innovation processes. International Journal of Operations and Production Management, 33(3), 275-295. DOI: I0.1 I08/0|44357|3| |300773.

PENG, D.X.,Schroeder, R. G. and Shah, R. (20I I). Competitive priorities, plant improvement and innovation capabilities, and operational performance. International Journal of Operations and Production Management, 3I(5), 484-5I0. DOI: |0.| | 08/0 |44357| I | | | 26292.

RAYMOND, L.; St-Pierre, J. (2010). R\&D as a determinant of innovation in manufacturing SMEs: an attempt at empirical clarification. Technovation, 30(I), 48-56. DOI: 10.1016/j. technovation.2009.05.005.

RUSJAN, B. (2005). Model for manufacturing strategic decision making. International Journal of Operations and Production Management, 25(8), 740-76I. DOI: 10.1 108/01443570510608583.
SEBRAE (20II). Taxa de sobrevivência das empresas no Brasil, SEBRAE, Rio de Janeiro.

SKILTON, P.F.and Dooley, K.(2002).Technological knowledge maturity, innovation and productivity. International Journal of Operations and Production Management, 22(8), 887-90I. DOI: 10.1 108/01443570210436190.

SKINNER, W. (1969). Manufacturing: the missing link in corporate strategy. Harvard Business Review, 47(3), |36-145.

THEODOROU, P. and Florou, G. (2008). Manufacturing strategies and financial performance - the effect of advanced information technology: CAD/CAM systems. Omega, 36(I), I07-I2I.DOI: 10.1016/j.omega.2005.10.005.

VACHON, S.; Halley, A. and Beaulieu, M. (2009). Aligning competitive priorities in the supply chain: the role of interactions with suppliers. International Journal of Operations and Production Management, 29(4), 322-344. DOI: I0.I I08/0 I4435709I0945800.

VOSS, C.A. (1995). Alternative paradigms for manufacturing strategy. International Journal of Operations and Production Management, I5(4),5-I6.DOI: I0.I I08/0I4435795I0083587.

VOSS, C., Tsikriktsis, N., Frohlich, M. (2002). Case research in operations management. International Journal Of Operations and Production Management, 22(2), 195-219. DOI: 10.1 I08/0I4435702104|4329.

YIN, R. (2003). Case study research: design and methods. Sage Publications, California.

WARD, P. and Duray, R. (2000). Manufacturing strategy in context: environment, competitive strategy and manufacturing strategy. Journal of Operations Management, $18,123-138$.

WEERAWARDENA, J. and Mavondo, F.T. (20I I). Capabilities, innovation and competitive advantage. Industrial Marketing Management, 40(8), I220-I223. DOI: 10.1016/j. indmarman.20II.10.0I2.

WHEELWRIGHT, S. C. (1984). Manufacturing strategy: defining the missing link. Strategic Management Journal, 5(I), 77-9I. DOI: I0.1002/smj.4250050I06.

WHEELWRIGHT, S. C.; Bowen, H. K. (1996). The challenge of manufacturing advantage. Production and Operations Management, 5(I), 59-77. DOI: I0.III I/j.1937-5956.1996. tb00385.x. 